\section{A clinical opportunity for routine HIV testing}

Thank you for publishing the editorial "Seek and Treat to Optimize HIV and AIDS Prevention."' This article raises a number of important points about HIV screening but unfortunately contains a significant error. That "Canada has no recommendation for routine [HIV] testing outside of prenatal screening and screening of the blood supply."' is simply not the case. That routine HIV testing of patients with tuberculosis (TB) was overlooked must have been unintentional. The World Health Organization continues to recommend routine, universal HIV testing of patients with TB because much of the global resurgence of TB in recent years is attributable to HIV and the synergy between these diseases. In Canada, multiple official statements and peer-reviewed publications dating back to 1992 , have recommended routine, universal HIV testing of patients with TB. ${ }^{2-7}$ In Alberta, where universal HIV testing of patients with TB has been applied since 2003, population and age groups with extraordinarily high rates of disease have been identified. In particular, Aboriginal people aged 15 to 64 and those from sub-Saharan Africa aged 15 to 64 have HIV coinfection rates of $14.7 \%$ and $20.9 \%$, respectively. ${ }^{7}$ Nevertheless, national compliance with the recommendation to test patients with TB for HIV remains poor, as highlighted by the HIV status of only $41 \%$ of patients with TB being known in 2008.8

In Canada, "opt-out" HIV testing of patients with TB has been shown to be both feasible and acceptable. ${ }^{6,7}$ Not screening patients with HIV for TB or not offering to screen patients with TB for HIV may be considered a dereliction of our duty.

\section{Richard Long MD, Deanne Langlois-}

\section{Klassen PhD}

Professor, Department of Medicine (Long), University of Alberta; and epidemiologist, Tuberculosis Program Evaluation and Research Unit (LangloisKlassen), University of Alberta,

Edmonton, Alta.

\section{References}

1. Gustafson R, Montaner J, Sibbald B. Seek and treat to optimize HIV and AIDS prevention. CMAJ 2012;184:1971.

2. Canadian Thoracic Society, Tuberculosis Directors of Canada, Department of National Health and Welfare in consultation with the provincial and territorial epidemiologists, AIDS coordinators and HIV caregivers. Guidelines for the identification, investigation and treatment of individuals with concomitant tuberculosis and HIV infection. CCDR 1992;18:155-60.

3. The Canadian Tuberculosis Committee of the Centre for Infectious Disease Prevention and Control, Population and Public Health Branch, Health Canada. Recommendations for screening and prevention of tuberculosis in patients with HIV and for screening for HIV in patients with tuberculosis and their contacts. CCDR 2002; 28 (ACS-7): 1-6.

4. Long R, Houston S, Hershfield E; Canadian Tuberculosis Committee of the Centre for Infectious Disease Prevention and Control, Population and Public Health Branch, Health Canada. Recommendations for screening and prevention of tuberculosis in patients with HIV and for screening for HIV in patients with tuberculosis and their contacts. CMAJ 2003;169:789-91.

5. The Canadian Tuberculosis Standards. 6th ed. Tuberculosis Prevention and Control, Public Health Agency of Canada, and the Canadian Lung Association/Canadian Thoracic; 2007.

6. Sturtevant D, Preiksaitis J, Singh A, et al. The feasibility of using an 'opt-out' approach to achieve universal HIV testing of tuberculosis patients in Alberta. Can J Public Health 2009;100: 116-20.

7. Long R, Boffa J. High HIV-TB co-infection rates in marginalized populations: evidence from Alberta in support of screening TB patients for HIV. Can J Public Health 2010;101:202-4.

8. Public Health Agency of Canada. Tuberculosis in Canada 2008. Ottawa (ON): The Agency; 2012.

CMAJ 2013. DOI:10.1503/cmaj.113-2113

\section{Climate change is a health issue}

As a physician who spent 6 months working on a pediatric malnutrition project in Djibouti in 2010 and who now lives in Yellowknife, NWT, which is already 2 degrees warmer than it was 50 years ago, ${ }^{1} \mathrm{I}$ am acutely aware of the effects of our changing climate. As an emergency doctor, I am also very familiar with the concept of time windows and the consequences of missing them. With the International Energy Agency telling us that we have a maximum of 5 years to start decreasing emissions, ${ }^{2}$ I would argue that this situation is comparable to a ST segment elevation myocardial infarction or to sepsis. We either get the job done in the next decade or so or we prepare for palliative care. As Sibbald mentioned in her edito- rial, ${ }^{2}$ our profession has not even begun to bring its powers to bear on the issue. We must start advocating at local, provincial, national and international levels to reframe climate change from its current perception as a political issue to what it truly is: a health issue. We must approach climate change in the same way we approach other critical medical issues (i.e., we push hard, we push fast and we don't stop).

I came across Sibbald's editorial ${ }^{1}$ in my email one morning while I was writing a grant proposal regarding an interactive website on the health effects of climate change. I had been communicating with film-makers and website developers to determine what they could contribute to the project. Such work has been somewhat lonely given the general lack of awareness of this issue amongst the Canadian medical community. The editorial by Sibbald ${ }^{3}$ buoyed my spirits. Thank you.

\section{Courtney Howard MD}

Emergency physician, Stanton Territorial Hospital, Yellowknife, NWT, and board member, Canadian Association of Physicians for the Environment, Toronto, Ont.

\section{References}

1. Renewing the Northwest Territories Greenhouse Gas Strategy 2011-2015. Northwest Territories Environment and Natural Resources. Yellowknife (NT); 2011.

2. Harvey F. World headed for irreversible climate change in five years, IEA warns. The Guardian (UK); 2011 Nov. 9.

3. Sibbald B. Physicians' roles on the front line of climate change. CMAJ 2013;185;195.

CMAJ 2013. DOI:10.1503/cmaj.113-2114

\section{Letters to the editor}

In submitting a letter, you automatically consent to have it appear online and/or in print. All letters accepted for print will be edited by $C M A J$ for space and style. Most references and multiple authors' names, full affiliations and competing interests will appear online only. (The full version of any letter accepted for print will be posted at cmaj.ca.) 